\title{
NOVOS PRODUTOS E ENERGIA A PARTIR DE BIOMASSA, UMA MATÉRIA PRIMA ABUNDANTE E RENOVÁVEL PARA O BRASIL
}

\author{
Felipe Moreton Chohfi - Departamento de Processos Químicos-DPQ - Faculdade de Engenharia Química-FEQ - \\ Universidade Estadual de Campinas, UNICAMP, fmchohfi@feq.unicamp.br \\ Gustavo Paim Valença - Departamento de Processos Químicos-DPQ - Faculdade de Engenharia Química-FEQ - \\ Universidade Estadual de Campinas, UNICAMP, gustavo@feq.unicamp.br
}

\section{RESUMO}

A biomassa consiste de qualquer fonte de carbono renovável advinda de fotossíntese que pode ser aproveitada de forma a obter combustíveis e novos produtos. Ao contrário dos outros recursos comumente classificados como combustíveis fósseis, em especial o carvão e o petróleo, a biomassa esta disponível por todo Brasil distante dos locais onde há petróleo. O Brasil detém vocação para produção de biomassa por conter climas tropicais e equatoriais, com grande intensidade solar e disponibilidade de água. São diversos os tipos de biomassa que podem ser convertidos em energia e novos produtos, entre elas, o capim-elefante, dendê, eucalipto, bambu, cana-de-açúcar entre outros. O presente estudo visa avaliar a tecnologia de termo-conversão de biomassa em um gás de síntese $^{1}$ para valoração como um insumo energético ou na produção de novos produtos. São diversas as aplicações possíveis a partir do gás de síntese, entre elas podemos destacar a queima direta do gás para geração de energia elétrica com alta eficiência, produção de hidrogênio para células combustível, a síntese Fischer-Tropsh, síntese do metanol e Di-Metil Éter, DME e até a fermentação do gás de síntese como discutido neste artigo.

Palavras-chave: biomassa, gás de síntese, energia, novos produtos

\section{INTRODUÇÃO}

A tecnologia para a substituição da cadeia produtiva do petróleo já existe e o Brasil possui enorme vantagem competitiva para a produção dos substratos vegetais utilizados na produção de combustíveis como o etanol e o biodiesel. Portanto, a adoção dessas matrizes depende muito mais de ações de natureza política do que tecnológica. Entretanto, para a indústria petroquímica o quadro é completamente diferente e só agora se inicia o desenvolvimento tecnológico para a obtenção de matérias-primas a partir de fontes renováveis.

O uso da biomassa, mundialmente, vem se tornando cada vez mais popular em vista do seu apelo ambiental em substituição aos combustíveis fósseis na mitigação das mudanças climáticas. Na combustão de biomassa para energia, as emissões de carbono são compensadas pelo seqüestro da biomassa no seu cultivo.

A biomassa consiste de qualquer material de origem vegetal derivado da fotossíntese e inclui a fração previamente processada por animais. O seu uso vem sendo negligenciado em muitos países, uma vez que o principal desafio consiste na sua captação em um único ponto de processamento por se tratar de um recurso distribuído. O presente trabalho visa fazer uma avaliação da opção de aproveitamento integral da biomassa através da termo-conversão em gás de síntese do qual uma série de aplicações são possíveis.

\footnotetext{
${ }^{1}$ Gás composto essencialmente de monóxido de carbono $\mathrm{CO}$ e hidrogênio, $\mathrm{H}_{2}$.
} 


\section{A biomassa, seus constituintes e poder calorífico}

A biomassa pode ser dividida entre suas frações nobres, que consistem de grãos, sacarose e óleos vegetais e suas frações fibrosas que podem ser divididas em celulose, hemi-celulose e ligno-celulose como mostrado na figura 1 abaixo. As frações nobres contém grãos como açúcar e óleos e tendem a ser usadas diretamente para alimento. Estes consistem de uma pequena fração da biomassa em torno de $10 \%$ da mesma. Já alguns constituintes celulósicos podem ser convertidos em sacarose através da hidrólise enquanto que a lignina detém estrutura mais complexa e tende a ser normalmente aproveitada por processos de termo-conversão ou queima direta. Dentre os processos comumente aplicados à biomassa nobre, destacam-se a transesterificação e a fermentação para obtenção de biodiesel e etanol respectivamente.

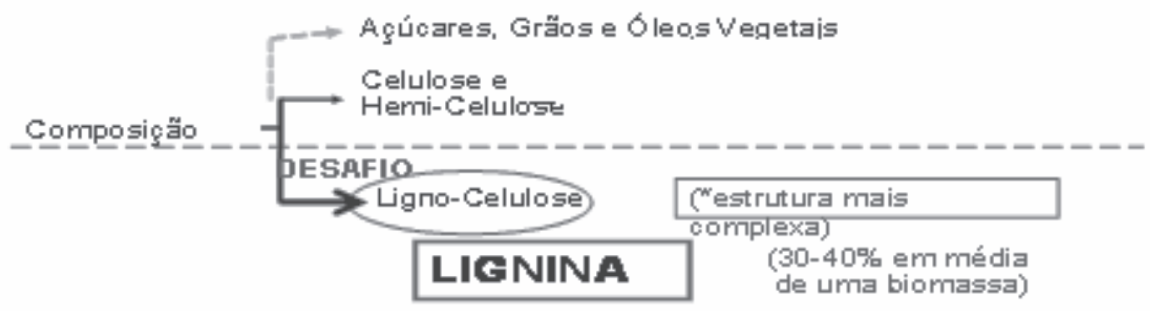

Figura 1. A biomassa e seus constituintes

A Tabela 1 mostra o conteúdo energético expressado em Poder Calorífico Inferior, $\mathrm{PCI}(\mathrm{kcal} / \mathrm{kg})$ de algumas biomassas. O poder calorífico inferior é o valor energético mínimo da biomassa. Ou seja, um kg de casca de amendoim libera mais energia ao ser queimada do que a mesma quantidade de casca de arroz.

Tabela 1. Conteúdo energético de algumas biomassas

\begin{tabular}{|l|r|}
\hline Tipo de Biomassa & $\mathrm{PCl}(\mathrm{kcal} / \mathrm{kg})$ \\
\hline Casaca de Arroz & $3.384,09$ \\
\hline Milho & $3.000,00$ \\
\hline Trigo & $3.000,00$ \\
\hline Soja & $3.000,00$ \\
\hline Coco & $4.556,82$ \\
\hline Casca de Amendoim & $4.281,82$ \\
\hline Casca de Castanha de Caju & $4.281,82$ \\
\hline
\end{tabular}

A análise elementar de algumas biomassas brasileiras foi pesquisada pelo Grupo de Energia de Biomassa e Meio Ambiente da UFPA. As biomassas pesquisadas foram a casca de arroz, o pinheiro e o caroço de açaí, gerando resultados de relação $\mathrm{C}, \mathrm{HeO}$ de 38,$3 ; 4,4$ e 35,5; 59; 7,2 e 32,7 e fi- nalmente 46,$0 ; 6,0$ e 46,0 respectivamente. Os resultados de enxofre e nitrogênio não foram encontrados para o pinheiro e são mínimos para a casca de arroz com valores de 0,06 e 0,83 . No caso apenas 0,8 em massa de nitrogênio foi encontrado (UFPA, 2007). 


\section{Biomassa como um Material Renovável no Brasil}

O Brasil se apresenta como o país com maior potencial para aproveitamento de biomassa. Os recursos presentes no Brasil abrangem desde os setores florestais onde ocupa o papel de grande produtor de carvão vegetal, e incluí também os setores marinhos e agrícolas onde o país se apresenta com grande produtor de algas e resíduos agrícolas como aqueles advindos do processamento agroindustrial da indústria canavieira, por exemplo. O Brasil é o maior produtor de carvão vegetal do mundo (ROCHA, J. 2007) obtido primariamente de eucalipto.

A biomassa potencialmente aproveitável é aquela que não tem mercado formado e que possa ser encontrada centralizada. Outros tipos de biomassa que podem ser potencialmente aproveitáveis incluem podas de árvores, pinhão manso, marmeleiro, urucum, cupuaçu e colza. As culturas de biomassas com maior potencial produtivo são de alto potencial fotossintético e assim tendem a ser encontradas na faixa equatorial pela maior intensidade solar e de chuvas. A produtividade agrícola compreende a produção da biomassa por hectare de plantação. Um hectare consiste de $10.000 \mathrm{~m}^{2}$. Cada cultura tem as suas características anuais no que concerne à safra e umidade. Neste sentido, foram consideradas suas produtividades em Ton b. s. (base seca)/hectare/ano na Tabela 2 a seguir:

Tabela 2. Produtividades agrícolas de diversas biomassas brasileiras

\begin{tabular}{|c|c|c|c|c|c|c|}
\hline Biomassa & Ton/ha/ano & Ton/ha/ano & Ton/ha/ano & Média & Umidade & Ton b.s/ha/ano \\
\hline Algas & 60 (i) & & & 60 & $0,319(x v)$ & 40,86 \\
\hline "Eichornia Crassipes" & 200 (i) & & & 200 & 0,319 & 136,2 \\
\hline "Aguapé" & $100(i)$ & & & 100 & 0,319 & 68,1 \\
\hline "Spirulina" & $92(v)$ & & & 92 & 0,319 & 62,65 \\
\hline Amendoim & $0,8(x i)$ & & & 0,8 & 0,2 & 0,64 \\
\hline Babacu & $3,6(i)$ & 15,6 (iii) & 2,15 (ix) & 7,16 & 0,2 & 5,728 \\
\hline Bamboo & 60 (iv) & & & & 0,3 & $12,5(x i i)$ \\
\hline Beterraba & 31,9 (i) & 7,5 (iii) & & 19,7 & 0,4 & 11,82 \\
\hline Cachos dendê & 6 (i) & 5 (vi) & 30 (viii) & 13,66 & 0,2 & 10,93 \\
\hline Cachos mamona & 6 (i) & 0,92 (vi) & $1,0(x i)$ & 2,64 & 0,2 & 2,11 \\
\hline Capim elefante (napier) & 20 (iii) & & & & 0,11 (xiv) & 25 (xvii) 45 (xvi) \\
\hline Cana & 100 (ii) & 87 (vii) & $120(x)$ & 102,33 & 0,6 & 40,93 \\
\hline Casca de arroz & 4,9 (xiii) & & & 4,9 & 0,2 & 3,92 \\
\hline Caroço de açaí & $8(x \mathrm{ix})$ & & & 8 & 0,1 & 7,2 \\
\hline $\begin{array}{l}\text { Eucalipto } \\
\text { Girassol }\end{array}$ & $\begin{array}{l}30 \text { (iii) } \\
1,9 \text { (i) }\end{array}$ & $\begin{array}{l}40 \text { (vii) } \\
2,4 \text { (vii) }\end{array}$ & $\begin{array}{l}1,5(\mathrm{xii}) \\
1,5(\mathrm{xi})\end{array}$ & $\begin{array}{c}23,83 \\
1,93\end{array}$ & $\begin{array}{l}0,2 \\
0,2\end{array}$ & $\begin{array}{c}19,06 \\
1,54\end{array}$ \\
\hline Madeira serrada & & & & & 0,19 (xiv) & $22,5(x x)$ \\
\hline Mandioca & 20,18 (i) & & & 20,18 & 0,5 & 10,09 \\
\hline Milho & 7,5 (iii) & 24 (vii) & 2,6 (iii) & 11,36 & 0,4 & 6,816 \\
\hline Palha e casca de café & 5,45 (xviii) & & & 5,45 & 0,1 & 4,905 \\
\hline
\end{tabular}

(i) ELETROBRÁS, 1978; (ii) NOGUEIRA, L et al. 2000; (iii) LEITE, R. et al. 2005; (iv) SITE DO GRUPO SANTOS, acesso 23/06/2008; (v) TEIXEIRA, C.; (vi) SITE DA SECRETARIA DA AGRICULTURA BAHIA, acesso 14/06/2008; (vii) CORMA, A; IBORRA, S; HUBER, G. 1996; (viii) SCAVARDA, L. 2006; (ix) TEIXEIRA, 2008; (x) HASUANI, S. 2005; (xi) CADERNOS NAE, 2005; (xii) BIZZO, W.
2007; (xiii) IRRI, 1995, PANDEY 1998BERNI, R. 2001; (xiv) SITE US DEPT OF ENERGY, acesso 28/06/2008; (xv) SITE ECN PHYLLIS, acesso em 29/06/2008; (xvi) MAZZARELLA, 2007- VILELA, H e CERIZE, D. "007; (xvii) ANDREOLI, C. 2008; (xviii) LEAL, J. 2002; (xix) VASCONCELOS, M; ALVES, S. 2006; (xx) ZERBE, J. 1985. 


\section{Gaseificação de biomassa em gás de síntese}

O uso de biomassa consiste de um insumo propício à combustão direta para produção de calor e energia devido ao seu alto poder calorífico e teor de oxigênio, o que possibilita uma fácil queima desse material. No entanto, a conversão térmica de biomassa em um gás de síntese também pode ser obtida e consiste em uma combustão parcial a temperaturas e pressões elevadas.

Mundialmente, a principal fonte de obtenção do gás de síntese é o gás natural por uma reação de reforma a vapor. No entanto, a tecnologia de gaseificação, envolvida na conversão de biomassa em gás de síntese, já está bem desenvolvida. A gaseificação consiste na conversão térmica da biomassa em um gás de síntese através da combustão parcial em temperaturas e pressões elevadas na faixa de $1000^{\circ} \mathrm{C}$ e 30 Bar. O agente de gaseificação consiste de ar, vapor d água, oxigênio ou uma mistura de gases, todos em quantidades inferiores à mínima para uma combustão completa. Uma equação química geral para a reação de gaseificação de biomassa com vapor d’água está mostrada abaixo:

$$
\mathrm{C}_{x} \mathrm{H}_{y} \mathrm{O}_{z}+(x-z) \mathrm{H}_{2} \mathrm{O} \rightarrow x \mathrm{CO}+\left(x-z-\frac{y}{2}\right) H_{2}
$$

\section{Variáveis do Processo de Gaseificação}

As variáveis do processo de gaseificação podem ser manipuladas de forma a obter um gás de síntese de boa qualidade. Conforme (CORMA, A. 2006) a composição do gás advindo do reator de gaseificação depende da composição da biomassa (insumo), condições do processo de gaseificação e agente gaseificador, como mostrado a seguir:

\section{1) Composição e forma da biomassa:}

A composição elementar de diferentes biomassas ou matérias primas (como resíduos sólidos urbanos) submetidas à gaseificação interferem na qualidade do gás de síntese gerado uma vez considerados que toda massa elementar desta matéria pode ser transferida para o gás de síntese. No caso da biomassa esta mesma contém além do $\mathrm{C}, \mathrm{H}$ e $\mathrm{O}$, que são frações desejadas, algumas frações indesejadas como o S, CL e N e traços de Pe Si. Além disso, a biomassa não contém minerais que são fundamentais.

Conforme estudo de AJF. Saraiva, a biomassa ideal deverá conter em geral $50 \%$ de carbono em base seca e terá de ter nas mesmas bases $16,5 \%$ de hidrogênio. Outro fator a ser considerado são as características de tipo e forma da biomassa utilizada, além de ser empregada "in natura" a biomassa pode ser empregada em fora de briquete, carvão vegetal ou bio-óleo. No caso do bio-óleo, por exemplo, uma biomassa líquida, a sua gaseificação facilita o uso de processos a altas pressões o que é impraticável com biomassas no estado sólido como o bagaço ou palha de cana. Conforme (ROCHA, J; MESA-PÉREZ，J; CHOHFI, F. 2007) a aplicação de processos de alta pressão em atmosfera controlada um gás de síntese de melhor qualidade.

2) Parâmetros do processo de gaseificação e agente gaseificador:

\section{a) Gaseificação com oxigênio puro:}

Processos de oxidação parcial usam menos do que a quantidade estequiométrica de oxigênio necessária para a combustão completa. O ajuste desta equação termoquímica abaixo pode gerar um gás de síntese de relação mássica $\mathrm{H} / \mathrm{C}$ de 10:36:

$$
\mathrm{C}_{6} \mathrm{H}_{10} \mathrm{O}_{5}+1 / 2 \mathrm{O}_{2} \quad 6 \mathrm{CO}+5 \mathrm{H}_{2}
$$




\section{b) Gaseificação com vapor de água:}

A reforma a vapor envolve a reação de água com uma matéria prima de biomassa para produzir o $\mathrm{CO}, \mathrm{CO}_{2}$ e $\mathrm{H}_{2}$. $\mathrm{O}$ ajuste dos parâmetros desta reação pode adicionar hidrogênio à biomassa resultando em uma relação mássica $\mathrm{H} / \mathrm{C}$ de 1:3:

$$
\begin{gathered}
\mathrm{C}_{6} \mathrm{H}_{10} \mathrm{O}_{5}+\mathrm{H}_{2} \mathrm{O} \quad 6 \mathrm{CO}+6 \mathrm{H}_{2} \\
\text { (CORMA, A, 2006) }
\end{gathered}
$$

Ao se empregar o vapor de água como agente gaseificador em condições supercríticas $\left(374^{\circ} \mathrm{C}\right.$ e $\left.218,3 \mathrm{~atm} \mathrm{~A}\right)$ é possível, por exemplo, introduzir-se mais hidrogênio à biomassa segundo estudos de AJF Saraiva.

A gaseificação de biomassa em elevadas condições de pressão favorece a formação do metano e dióxido de carbono, já os aumentos de temperatura levam a elevadas concentrações de hidrogênio e monóxido de carbono. O vapor é normalmente usado como o agente de gaseificação na produção do gás de síntese. O uso de catalisadores (por exemplo Ni) em conexão com a gaseificação a vapor contribui para o aumento do conteúdo de hidrogênio no gás de síntese (SPECHT, M. ).

\section{3)Adição de catalisadores:}

A adição de um catalisador pode afetar a taxa da reação e reduzir impurezas assim como promover a seletividade de determinados produtos como o hidrogênio em detrimento de outros como o metano.

O uso de catalisadores para redução da produção do alcatrão já foi investigado. Os catalisadores operam ao reagir com o alcatrão para formar o coque e depois promover a oxidação do mesmo para aumentar a conversão de gases (DIEBOLD, J; STEVENS, D. _).

Uma forma de reduzir a concentração de alcatrão no gás de síntese é a adição de catalisadores dentro do reator, o que requer um gás de síntese de alta pureza (SPECHT, M. )
Catalisadores que já foram adicionados dentro de reatores de gaseificação incluem $\mathrm{Pd}, \mathrm{Pt}$, $\mathrm{Ru}$ e $\mathrm{Ni}$ suportados com $\mathrm{CeO}_{2} / \mathrm{SiO}_{2}$ e dolomita. $\mathrm{Rh} / \mathrm{CeO}_{2} / \mathrm{SiO}_{2}$ foram os cata-lisadores mais efetivos na redução dos níveis de alcatrão. Os catalisadores baseados em niquel também têm sido testados em estudos de Backer et al. Porém, houve uma desativação rápida do catalisador devido à formação do coque e atrito com o catalisador (CORMA, A. 2006).

\section{Tecnologias e Reatores de Gaseificação}

O reator onde ocorre a conversão térmica da biomassa em gás e síntese pode ser considerado o principal componente da tecnologia de gaseificação. Os reatores de gaseificação podem ser divididos em leito fixo e fluidizado. Os reatores de leito fixo são mais fáceis de projetar e operar e têm alta eficiência na conversão de carbono em gás de síntese e baixa produção de cinzas e alcatrão. São excelentes para insumos de alta densidade e granulometria grossa. Já o leito fluidizado, por outro lado, contém areia o que promove uma intensa circulação e mistura das partículas de biomassa. Neste reator a temperatura de operação é limitada pelas características de fusão e cinzas.

A gaseificação de biomassa em larga escala deve ser feita em reatores de leito fluidizado, porém, essa tecnologia gera gás de síntese com alto teor de particulado e alcatrão, frações indesejáveis no processo. Por outro lado, os reatores de leito fixo geram um gás de síntese muito mais limpo e isento de contaminantes, porém, não permite scaleup para grandes capacidades. Uma solução para isto, seria a gaseificação em grande escala usando leito fluidizado e biomassa líquida na forma de bio-óleo, o que garante a aplicação de processos de alta pressão, e consequentemente um gás isento de impurezas e frações indesejáveis à síntese catalítica. 
Dentro das características construtivas da tecnologia de gaseificação outros fatores técnicos podem ser variados como a direção de entrada do fluxo de combustível (biomassa) e do agente de gaseificação, assim, podendo ser classificada em "updraft" onde o gás flui em direção ao topo do leito, "downdraft" onde o gás flui para baixo e até fluxo cruzado, por onde o combustível é inserido pela parte superior do reator e o agente de gaseificação pela parte inferior em fluxo cruzado.

\section{Tecnologias e Processos de Limpeza e Condicionamento do Gás de Síntese}

A presença de impurezas no gás advindo da gaseificação como o cloro, enxofre, amônia e particulados são inevitáveis e devem ser removidas durante a limpeza do gás de síntese. As aplicações do gás de síntese são variadas e estabelecem requerimentos específicos de qualidade e condicionamento do gás no que diz respeito ao seu poder calorífico, concentração dos componentes principais e de impurezas. Neste sentido, tecnologias e processos de limpeza e condicionamento do gás de síntese são necessários para ajustar as características do gás à aplicação pretendida.

$\mathrm{Na}$ Figura 2 abaixo são mostrados alguns dos diversos processos de conversão do gás de síntese possíveis de serem empregados assim como suas demandas de catalisadores especificas. Diferentes equipamentos, por exemplo, purificadores, compressores, refrigeradores entre outros podem ser utilizados para este fim sendo licenciados por empresas como a Toyo Engineering e JFE Holdings.

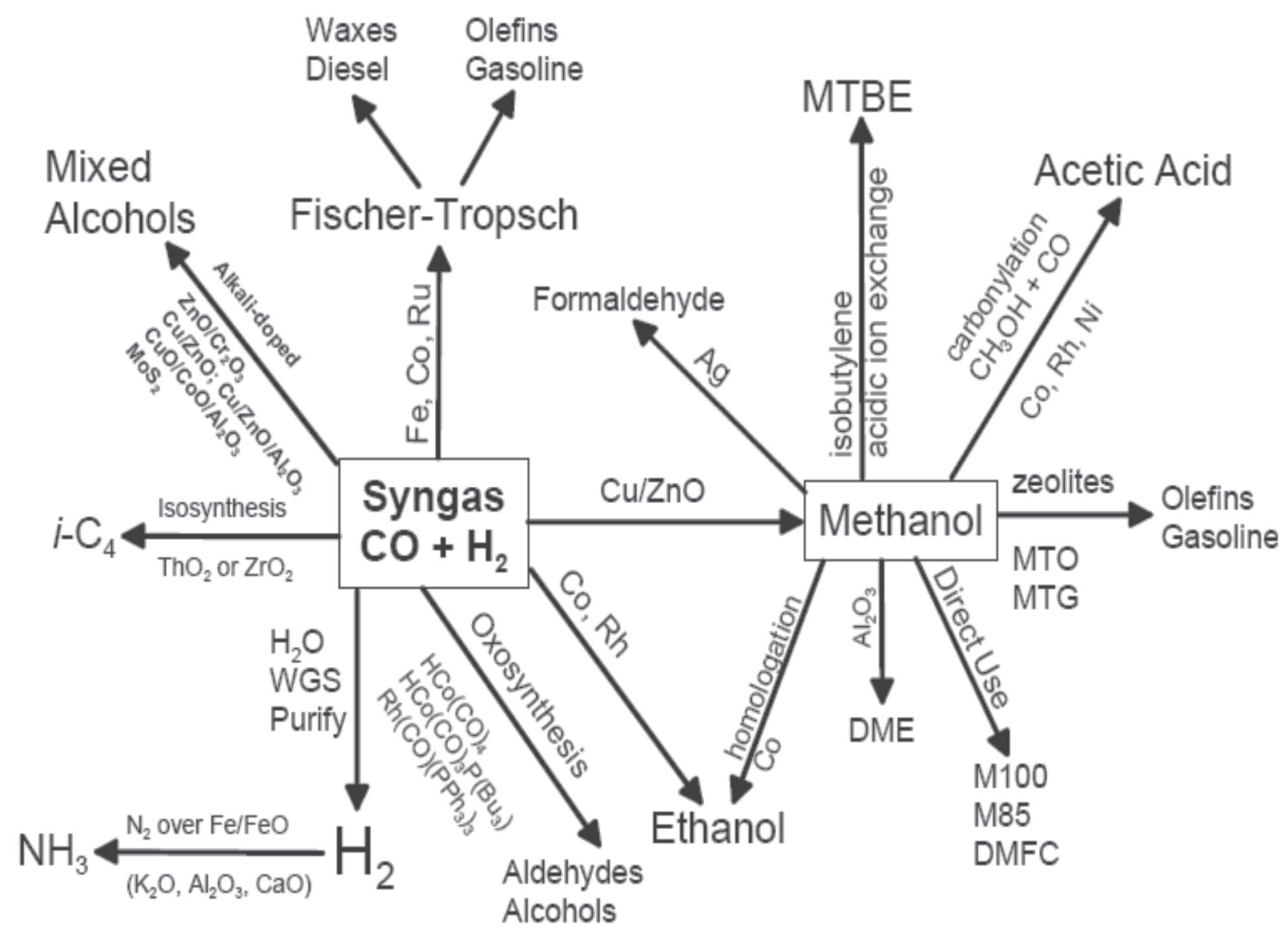

Figura 2. Alguns processos de conversão do gás de síntese (DAYTON, SPATH. 2003). 
A relação $\mathrm{H}_{2} / \mathrm{CO}$ no gás pode ser ajustada durante o condicionamento visando adequar as características do gás de síntese aos requerimentos dos processos de conversão pretendidos. Um exemplo dos processos de condicionamento é a reação de deslocamento do gás d’água (4):

$$
\mathrm{CO}+\mathrm{H}_{2} \mathrm{O} \quad \square \quad \mathrm{CO}_{2}+\mathrm{H}_{2}
$$

O craqueamento catalítico do alcatrão permite a reforma destes hidrocarbonetos, que não foram completamente convertidos em gás de síntese, em contato com o catalisador e com vapor ou $\mathrm{CO}_{2}$ ou ambos aumentando os teores de $\mathrm{H}_{2}$ e $\mathrm{CO}$ no gás de síntese como mostrado nas reações (6) e (7) abaixo. O catalisador preferível para esta reação é a dolomita natural (RAPAGNA, S, 2000-WANG, L. 2008):

$$
\begin{aligned}
& C_{n} H_{2 m}+n H_{2} \mathrm{O} \Leftrightarrow n C O+\left(n+\frac{m}{2}\right) H_{2} \\
& C_{n} H_{m}+n \mathrm{CO}_{2} \Leftrightarrow 2 n C O+\left(\frac{m}{2}\right) H_{2}
\end{aligned}
$$

No tratamento do gás de síntese a remoção de impurezas pode ser obtida por meio de filtros e catalisadores. O filtro de mangas consiste de uma nova geração de filtros de fibra de vidro e uma temperatura máxima de operação do gás de $260^{\circ} \mathrm{C}$ (PERRY et al., 1987). Nesta temperatura os particulados e os álcalis podem ser satisfatoriamente removidos (CONSONNI; LARSON, 1994; TIJMENSEN, 2000).

A remoção dos álcalis é finalizada num lavador de gás (CONSONNI; LARSON, 1994). Um leito de $\mathrm{ZnO}$ é suficiente para diminuir a concentração de enxofre até valores inferiores a $0,1 \mathrm{ppm}$. O mesmo pode ser operado numa faixa de temperaturas entre $50 \mathrm{e}$ $400^{\circ} \mathrm{C}$. Em baixas temperaturas e pressões a quantidade de enxofre absorvido é menor, portanto leitos múltiplos serão usados em série. O $\mathrm{ZnO}$ pode ser utilizado somente durante um ano e não é possível regenerá-lo (KATOFSKY, 1993).
Para temperaturas acima de $400^{\circ} \mathrm{C}$ a remoção de partículas se faz em filtros de leito granular fino em vez de ciclones. A remoção final das partículas é feita usando filtros de cerâmica ("candle") (HAMELINCK et al., 2002) ou placas de metal sinterizado, operando a temperaturas acima de $720^{\circ} \mathrm{C}$ com eficiências superiores a 99,8\% para partículas de 2-7 $\mu \mathrm{m}$ (KATOFSKY, 1993). Ainda podem ser utilizados filtros cerâmicos para a remoção simultânea de $\mathrm{SO}_{x}, \mathrm{NO}_{\mathrm{x}}$ e particulados (WHITE et al. 1992).

Catalisadores base níquel têm demonstrado alta eficiência para a decomposição da mistura de alcatrão, amônia e metano no gás da gaseificação de biomassa a temperaturas em torno de $900^{\circ} \mathrm{C}$. Porém, o enxofre pode envenenar estes catalisadores (TIJMENSEN, 2000). Ainda não se tem certeza se os componentes de nitrogênio HCN podem ser removidos. Os alógenos são removidos mediante adsorventes pulverizados baseados em $\mathrm{Na}$ e $\mathrm{Ca}$. Estes são injetados no fluxo de gás e removidos nos separadores de particulados (VERSCHOOR et al., 1991).

\section{Aplicações para o Gás de Síntese}

Conforme (ANNEVELINK, REE VAN. 2007) uma biorefinaria consiste de uma unidade de processamento sustentável de biomassa em diversos produtos verdes e energia comercializável. Entre as diversas possibilidades, uma biorefinaria que processa biomassa lignocelulósica tem duas possibilidades: primeiramente atua na separação de seus componentes de forma a aplicar processos diferenciados, ou seja, divide a biomassa em lignina, hemi-celulose e celulose. Por outro lado uma distinção deve ser feita da biorefinaria termo-química, onde processos como a pirólise e a gaseificação são aplicados em toda biomassa sem a necessidade de prévia separação. 


\section{1) Geração de Eletricidade:}

Tecnologias modernas como a BIG/GT-CC (Biomass Integrated Gasifier/Gas Turbine-Combined Cycles) podem aumentar a eficiência e reduzir os custos da geração de energia elétrica. A eficiência obtida com este processo, definida pela energia do gás combustível em comparação à energia do material orgânico usado na gaseificação é alta chegando a 80$85 \%$. A previsão e uma eficiência final para conversão de biomassa em eletricidade de $45 \%$ com o uso de ciclos combinados (LEITE, R.etal. 2005).

Os projetos de geração de eletricidade com gás de síntese têm se focado principalmente na geração em regiões isoladas e em comunidades de baixa renda. A principal dificuldade que se apresenta nesta opção consiste da queima de um gás de baixo poder calorífico por conter elevadas frações de gás natural, e outros gases como o nitrogênio que geram um baixo poder calorífico.

De acordo com (BRIENS, C. 2008) para a produção elétrica o ar é usado como agente gaseificador devido ao elevado custo do oxigênio, desta forma o gás produzido pode ser usado e queimado em uma turbina diretamente para produção de eletricidade. Um gás de baixo poder calorífico advindo da gaseificação de biomassa com ar pode ser fornecido a um combustor para geração de energia (RASKIN, N et al. 2001- WANG, L et al. 2008). Turbinas a gás podem transformar gás de síntese quente para energia mecânica assim aumentando a eficiência de conversão energética(WANG et al. 2008).

2) Produção de Hidrogênio em Células Combustível:

Conforme (HERNÁNDEZ PACHECO, E et al. 2005; IAQUANIELLO, G et al. 2006). Uma célula combustível utiliza o $\mathrm{H}_{2}$ e $\mathrm{O}_{2}$ para produzir eletricidade e gera calor com um subproduto na presença de um material condutor eletrólito. Por ser $\mathrm{O}_{2} \mathrm{O}$ único combustível eletro-químicamente ativo dentro da célula combustível o $\mathrm{CH}_{4}$ presente no gás deve ser convertido em hidrogênio usando a reação de reforma do metano (7) (WANG, L et al. 2008) ou a reação de decomposição do metano (8):

$$
\mathrm{CH}_{4}+\mathrm{CO}_{2} \log 2 \mathrm{H}_{2}+2 \mathrm{CO}
$$

$\mathrm{CH}_{4} \quad \log \mathrm{C}+2 \mathrm{H}_{2}$

A outra reação usada contínuamente na reforma do gás para $\mathrm{H}_{2}$ é a reação de deslocamento do gás d’água (water-gas shift) já mencionada anteriormente. $O$ hidrogênio pode ser continuamente produzido à medida que o componente $\mathrm{CO}$ do gás de síntese é transformado em hidrogênio e $\mathrm{CO}_{2}$ durante a aplicação contínua da reação de shift água- gás com o uso de catalisadores Cobre-Zinco e adsorção de $\mathrm{CO}_{2}$ usando um adsorvente com o $\mathrm{CaO}$ mostrado na reação abaixo (9), gera o hidrogênio puro (WANG et al. 2008- LV, P et al. 2004). A adsorção pode remover o $\mathrm{CO}_{2}$ do fluxo de gás (WANG et al. 2008- HANAOKA, Tetal. 2005).

$\mathrm{CaO}+\mathrm{CO}_{2} \log \mathrm{CaCO}_{3}$

Atualmente o principal mercado para o hidrogênio é como combustível em células combustível. As células combustível são baterias de funcionamento contínuo, ou seja, conversões diretas de energia química em energia elétrica e térmica que produzem uma corrente pela combustão eletroquímica a frio do hidrogênio.

\section{3) Síntese Fischer-Tropsh:}

A produção Gas-to-Liquids, GTL usando a tecnologia Fischer-Tropsch tem sido usada comercialmente para a gaseificação do carvão e reforma do gás natural partindo do gás de síntese. A empresa SASOL na África do Sul chegou a produzir $40 \%$ da combustível do país usando esta tecnologia. Apesar de ser uma alternativa cara, a síntese Fischer-Tropsch 
pode produzir combustíveis sintéticos.

Uma mistura de gás contendo $\mathrm{CO}$ e $\mathrm{H}_{2}$ pode ser usada para produzir hidrocarbonetos de correntes $-\mathrm{CH}_{2}-$ de tamanho variável. A reação de síntese Fischer-Tropsch está mostrada na reação (10) a seguir:

$$
\mathrm{CO}+2 \mathrm{H}_{2}-\mathrm{CH}_{2}-+\mathrm{H}_{2} \mathrm{O}
$$

(WANG, L et al. 2008)

O diesel produzido pela síntese de Fischer-Tropsch, por exemplo, consiste de correntes de $-\mathrm{CH} 2-\operatorname{com} 9-25$ átomos de carbono. Este diesel pode ser mesclado ao diesel comum e usado em motores convencionais quando mesclado ao diesel. Além do diesel, outros produtos incluem olefinas, álcoois e ácidos (OLOFSSON, I et al. 2005).

Para esta reação, a relação molar de $\mathrm{H}_{2} / \mathrm{CO}$ no gás deve ser mantida em 2:1 e os catalisadores comuns são os metais de transição do grupo 8 da tabela periódica e que são considerados bons catalisadores de hidrogenação. A síntese de Fischer-Tropsch pode ocorrer em baixas ou altas temperaturas 200 a $250^{\circ} \mathrm{C}$ ou altas temperaturas 300 a $350^{\circ} \mathrm{C}$, para síntese de gasolina e olefinas $\left(\mathrm{C}_{3}\right.$ $\mathrm{a}_{11}$ ) a pressão de operação é de $10 \mathrm{a} 40 \mathrm{Bar}$.

\section{4) Síntese do metanol e Di-Metil Éter:}

O metanol é um composto químico pertencente à família do álcoois. Detém a característica de alta versatilidade por poder ser utilizado como combustível diretamente, por exemplo em aviões, ou como uma matéria-prima para uma série de produtos químicos como o formaldeído. Mais de $85 \%$ do metanol produzido no mundo é oriundo do gás de síntese advindo da reforma a vapor do gás natural. Empresas licenciadoras de tecnologia de síntese de metanol incluem Haldor-Topsøe, ICI, JFE Japan, Toyo Engineering Corp., Chiyoda Corp., Lurgi GmB, BASF, GmB, Hunan Anchun Gaoxin Tech. Co.
A síntese do metanol, por exemplo, requer um gás de síntese com relação molar $\mathrm{H}_{2} / \mathrm{CO}=2$ e um teor de $\mathrm{CO}_{2}$ na faixa de 4 a $8 \%$ com condições de pressão e temperatura na faixa de 40 a 110 Bar e 200 a $300^{\circ} \mathrm{C}$, os conteúdos de gás metano devem ser mantidas em um mínimo. O catalisador utilizado é o cobre e óxido de zinco com suporte em óxido de alumínio e cromo.

$\mathrm{O}$ Di-Metil Éter $\left(\mathrm{C}_{2} \mathrm{H}_{6} \mathrm{O}\right)$ é o único produto da desidratação do metanol e consiste de um produto de alto valor na mesclagem com o Gás Liquefeito de Petróleo, GLP como combustível residencial ou na substituição do diesel em veículos automotores. Como combustível apresenta um valor calorífico superior ao do gás natural e pode ser liquefeito e armazenado em cilindros. Além disso, o DME tem sido aplicado na substituição dos clorofluorcarbonos, $\mathrm{CFC}$ em propelentes para aerossóis que vem destruindo a camada de ozônio.

5) Fermentação Biológica do Gás de Síntese:

O gás de síntese pode ser convertido em meio aquoso no contato com bactérias para o etanol, por exemplo, a empresa KOSKATTA é líder nesta tecnologia. Conforme BROWN (BROWN, 2006) fornece uma revisão sobre a fermentação do gás de síntese para produção de produtos biológicos. Foram investigadas diversas bactérias que utilizam o gás de síntese como fonte de carbono e energia para crescimento e produção biológica de uma larga gama de produtos. Conforme WANG (WANG, $\mathrm{L}$ et al. 2008) essas bactérias incluem butyribacterium metalotrophicum para 0 etanol e butanol (WORDEN, R. 1991) clostridial para o etanol (VEGA et al. 1989; DATAR, R. et al. 2004) e rodospirillus rubrum para $\mathrm{o} \mathrm{H}_{2}$ e poliesters. 
As vantagens da conversão biológica do gás de síntese sobre a catálise química são diversas. A maioria das bactérias anaeróbicas que fermentam o gás de síntese são tolerantes ao enxofre e pouco sensíveis às mudanças na relação $\mathrm{H}_{2} / \mathrm{CO}$. Além disso, a fermentação do gás de síntese não requer um processo complexo de limpeza de enxofre do gás e controle rígido da relação $\mathrm{H}_{2} / \mathrm{CO}$. Vale mencionar que um processo biológico como a fermentação ocorre a pressões e temperaturas modestas e a especificidade dos catalisadores é superior àquelas experimentadas com catalisadores químicos. Por outro lado, uma desvantagem seria a falta de crescimento e produção das bactérias o que ocasionaria em uma inibição do processo e uma barreira para esta tecnologia.

\section{CONCLUSÃO}

Há uma grande diversidade de biomassas potencialmente aproveitáveis em todo território brasileiro. A cana-de-açúcar e o milho são bons exemplos de biomassas que detém um mercado já estabelecido para suas frações nobres, porém detém um alto teor de água em suas composições o que implica em baixa produção de celulose para aproveitamento na geração de energia. A madeira, eucalipo, o capim elefante e as algas marinhas são aquelas biomassas que geram maiores produtividades em material celulósico fibroso seco por hectare/ano e devem ser considerados no Brasil. A tecnologia de conversão da biomassa celulósica em gás de síntese deve ser considerada, não apenas no aproveitamento de resíduos do processamento de grãos, mas como uma estratégia de sustentabilidade no aproveitamento dos recursos. No futuro, biorrefinarias capazes de cultivar diferentes biomassas, nobres e energéticas e produzir diversos produtos aplicando diferentes processos pode ser possível. A produção do gás de síntese nestas biorrefinarias seria a única alternativa de aproveitamento total da biomassa ligno-celulósica e apresenta uma com o gás de síntese que foram discutidas neste artigo.

\section{REFERÊNCIAS}

ANDREOLI, C. Convergência de Agricultura e Energia, Produção de Biomassa Celulósica para Biocombustíveis. Energia, http://ecen.com, Numero 66, ano XI, Fevereiro/Março de 2008;

ANNEVELINK; REEVAN. Status Report on Biorefinery. 2007;

BERNI, R. Efeito da Cinza da Casca de Arroz no Controle da Bruxunonse nas Folhas, Tese, Universidade Federal de Goiás; BIZZO, W. Tecnologias da Biomassa para Conversão de Energia, Rede Nacional de Combustão, 2007;

BOERRIGTER, H, Synthesis gas from biomass for fuels and chemicals. ECN Biomass Coal and Environmental research. Sweden. 2005;

CARABALLO, J. Ethanol Synthesis. 1st European Summer School on Motor Fuels, Abengoa Bioenergia, Germany, 2005;

CADERNOS NAE. Biocombustíveis. Brasília, 2005;

CORMA, A; IBORRA, S; HUBER, G. Synthesis of Transportation Fuels from Biomass: Chemistry Catalysts and Engineering Instituto de Tecnologia Quimica, Universidad politecnica de Valencia, Chem Review. 106, 4044-4098, Valencia, 2006;

CORMA, A. Synthesis of Transportation Fuels from Biomass: Chemistry, Catalysts, and Engineering. Chem. Rev. 2006, 106, 4044-4098. 2006;

CORTEZ, L; LORA, E; GOMÉZ, Biomassa para Energia, Editora da Universidade Estadual de Campinas. 2008;

DAYTON, D; SPATH, P. Preliminary Screening- Technical and Economic Assessment of Synthesis Gas to Fuels and Chemicals with Emphasis on the Potential for Biomass-Derived Syngas, Technical Report, National Renewable Energy Laboratory, NREL/TP-510-34929, United States of America, 2003; 
DIEBOLD, J; STEVENS, D. Pyrolysis and Gasification. Compilation Summary Articles; ECN PHYLLIS The Composition of Biomass a $n$ d $\mathrm{W}$ a s $\mathrm{t}$ e, http://www.ecn.nl/phyllis/group.asp, acesso em 29/06/2008;

ELETROBRÁS. Seminário sobre Energia de Biomassas no Nordeste, Fortaleza, 1978

NOGUEIRA, L et al. Dendroenergia: Fundamentos e Aplicações, ANEEL, Brasília, 2000;

FONZI, F. Pyrolysis and Gasification. Compilation Summary Articles;

GRUPO J O Ã O S A N TOS. site http://www.itapage.com $/ \mathrm{html} / \mathrm{materia}$ _prima. htm, acesso em 23/06/2008;

HASUANI, S. Biomass Power Generation, PNUD, Piracicaba, 2005;

HENRICH, E. The status of the FZK concept of biomass gasification. 2nd European Summer School on Motor Fuels, Poland, 2007;

ROCHA, J; MESA-PÉREZ, J; CHOHFI, F. Produção do Bio-DME a Partir de Biomasa. Universidade Estadual de Campinas, 2007;

LEITE, R. et al. Report for the IUPAP Working group on Energy from Biomass. FINEP, Campinas, 2005;

LEAL, J. Mapeamento da Produtividade na Colheita Mecanisada do Café. Escola Superior de Agricultura Luiz de Queiro Dissertação de Mestrado, USP, Piracicaba, 2002;

OLOFSSON, I; NORDIN, A; SODERLIND, U. Initial Review and Evaluation of Process Technologies and Systems Suitable for Cost-Efficient Medium Scale Gasification for Biomass to Liquid Fuels, Energy Technology and Thermal Process Chemistry, Umea University, Sweden, 2005;

ROCHA, J., D., et al. "The demonstration of the Fast Pyrolysis Plant of Biomass Conversion in Brazil". Proceedings of the VII World Renewable Energy Congress, 2002, Germany, ISBN 0080440 797;

SCAVARDA, L. Estudo de Caso da Cadeia de Suprimentos do Biodiesel: Caso da Dendeicultura na Bahia. V16, 1, p119; SECRETARIA DA AGRICULTURA. Governo da Bahia, SEAGRI, http://www.seagri.ba.gov.br/. Acesso em 24/06/2008;

SPECHT, M. Gasification of Biomass na Overview on available Technologies. Centre for Solar Energyand Solar Reearch. Germany

TEIXEIRA, C. Um novo sistema de cultivo de microalgas para produção de Biodiesel. Instituto Nacional de tecnologia Rio de Janeiro;

TEIXEIRA, M. Babassu. A New Approach for an Ancient Brazilian Biomass, Elsevier, Biomass and Bioenergy, number 1

US DEPT. OF ENERGY, ENERGY EFFICIENCY AND RENEWABLE ENERGY, http://eere.energy.gov/biomass/feedstock

VILELA, H e CERIZE, D. Capim Elefante Paraíso na Geração de Energia, Artigo Científico, Portal Agronomia

VASCONCELOS, M; ALVES, S. Sistema de Produção do Açaí. Emprapa Amazônia Oriental, Sistemas de Produção 4, 2a e Ediçao E l e trônica, disponíve 1 e m http://sistemasdeproducao.cnptia.embrapa.br/Fon tesHTML/Acai/SistemaProducaoAcai_2ed

WANG, L. "Contemporary issues in thermal gasification of biomass and its application to electricity and fuel production". Biomass and Bioenergy 32, 2008 573- 58;

ZERBE, J. Current Develpments in the Conversion of Wood to Liquid Fuels. In: Symposium on Forest Products Research dição, ISSN 1809-4325 and the Future. Vol 5. 1985. Pretoria, South African Council for Scientific and Industrial Research, National Timber research Institute, 1985, 10p. 